\title{
Climate Warming and Disease Risks for Terrestrial and Marine Biota
}

\author{
C. Drew Harvell, ${ }^{1 *}$ Charles E. Mitchell, ${ }^{1,2}$ Jessica R. Ward, ${ }^{1}$ Sonia Altizer, ${ }^{3,4}$ Andrew P. Dobson, ${ }^{5}$ Richard S. Ostfeld, ${ }^{6}$ \\ Michael D. Samuel ${ }^{7}$
}

Infectious diseases can cause rapid population declines or species extinctions. Many pathogens of terrestrial and marine taxa are sensitive to temperature, rainfall, and humidity, creating synergisms that could affect biodiversity. Climate warming can increase pathogen development and survival rates, disease transmission, and host susceptibility. Although most host-parasite systems are predicted to experience more frequent or severe disease impacts with warming, a subset of pathogens might decline with warming, releasing hosts from disease. Recently, changes in El Niño-Southern Oscillation events have had a detectable influence on marine and terrestrial pathogens, including coral diseases, oyster pathogens, crop pathogens, Rift Valley fever, and human cholera. To improve our ability to predict epidemics in wild populations, it will be necessary to separate the independent and interactive effects of multiple climate drivers on disease impact.

I nfectious diseases are strong biotic forces that can threaten biodiversity by catalyzing population declines and accelerating extinctions. Pathogens are implicated in recent declines of Australian and Central American frogs $(1,2)$, Hawaiian forest birds, and African wild dogs (3). Invertebrate extinctions associated with disease include the Polynesian tree snail (4) and a marine limpet (5). Pathogens also contribute to declines of threatened species such as lions (Fig. 1), cranes, eagles, and black-footed ferrets $(6,7)$. Plant pathogens can cause problems not only for their immediate hosts but also for their associated fauna and ecological communities. For example, the Asian chestnut blight fungus (Cryphonectria parasitica) effectively extirpated the American chestnut (Castanea dentata) from eastern United States forests (8), causing the apparent extinction of several phytophagous insects (9). In Australia, the root-infecting fungus Phytophthora cinnamomi converted large areas of Eucalyptus forest to monocot-dominated open savanna (10), eliminating potential nest

'Department of Ecology and Evolutionary Biology, Cornell University, Ithaca, NY 14853, USA. ²Department of Ecology, Evolution and Behavior, University of Minnesota, St. Paul, MN 55108, USA. ${ }^{3}$ Department of Environmental Studies, Emory University, Atlanta, GA 30322, USA. ${ }^{4}$ Cornell Laboratory of Ornithology, 159 Sapsucker Woods Road, Ithaca, NY 14850, USA ${ }^{5}$ Department of Ecology and Evolutionary Biology, Princeton University, Princeton, NJ 08544, USA. ${ }^{6}$ Institute of Ecosystem Studies, Box AB, 65 Sharon Turnpike, Millbrook, NY 12545, USA. ${ }^{7}$ U.S. Geological Survey-National Wildlife Health Center, Madison, WI 53711, USA.

*To whom correspondence should be addressed. Email: cdh5@cornell.edu sites and food for many animals $(11,12)$.

Anthropogenic climate change is having measurable effects on ecosystems, communities, and populations (13). Understanding links between infectious disease and climate is more difficult, given the paucity of baseline disease data, the multivariate nature of climate change, and nonlinear thresholds in both disease and climate processes (14). Associations between climate and disease do not necessarily imply causation, but results from correlational studies and short-term experiments can help us to separate the effects of climate from other components of global change. We review the potential consequences of temperature changes on infectious diseases and consider the hypothesis that climate warming will affect host-pathogen interactions by (i) increasing pathogen development rates, transmission, and number of generations per year; (ii) relaxing overwintering restrictions on pathogen life cycles (Fig. 2); and (iii) modifying host susceptibility to infection. Changes in these mechanisms could cause pathogen range expansions and host declines, or could release hosts from disease control by interfering with the precise conditions required by many parasites. Clearly, not all pathogens have equal potential to control host populations or to be affected by warming. We predict that climate warming will disproportionately affect pathogens with complex life cycles or those that infect nonhomeothermic hosts during one or more life cycle phases.

Despite known impacts of infectious diseases, the combined effects of climate change and disease on biodiversity have rarely been considered $(2,15-17)$. Difficulty in separat- ing directional climate change from shortterm variation has made it challenging to associate climate warming with disease prevalence or severity. For most wild populations, there are no long-term records of disease prevalence or baseline estimates of disease impacts on fitness. Recent work on human, crop, and forest pathogens, for which longterm data exist, shows sensitivity of some pathogens and vectors to climate factors (18$23)$. It is therefore likely that pathogens affecting wild populations will experience similar climate-driven changes.

\section{Climate: Current and Predicted Changes}

Terrestrial systems. The rate of climate change resulting from increased greenhouse gases and changes in land and water use is expected to be rapid on an evolutionary time scale (16). The Intergovernmental Panel on Climate Change (IPCC) (24) provides projections for terrestrial ecosystems. Mean global surface air temperature is projected to increase by $1.4^{\circ}$ to $5.8^{\circ} \mathrm{C}$ by 2100 relative to 1990, with the magnitude of the increase varying both spatially and temporally. Continental regions and higher latitudes are projected to warm more than coastal regions and the tropics. Nighttime minimum temperatures are expected to increase more than daytime maximum temperatures, and winter temperatures are expected to increase more than summer temperatures. Warming will alter other aspects of climate relevant to disease, particularly humidity and precipitation. Some areas will experience more intense precipitation events and increased humidity while others have an increased risk of drought. Generally, globally averaged water vapor pressure, evaporation, and precipitation are projected to increase (24). However, predicted changes in hydrologic variables are much less robust than changes in temperature, so we focus on the potential effects of temperature.

Marine systems. The direct components of predicted climate change affecting marine organisms over the next century are (i) temperature increase, (ii) sea level increase and subsequent changes in ocean circulation, and (iii) decrease in salinity (24). Coastal ocean temperature increases are expected to be slightly lower than the IPCC projected increases for land, but still rise measurably. Sea level is 


\section{SCIENCE'S COMPASS}

expected to rise by 0.09 to $0.88 \mathrm{~m}$. Effects on ocean circulation and potential climate feedbacks cause large uncertainty in many climate predictions. For example, the direction of the North Atlantic Oscillation, which influences temperate climate and has been hypothesized to affect Caribbean disease outbreaks (25), is determined by warming in tropical oceans (20). In addition to a mean increase in temperature, extremes are expected to increase and intermittent phenomena such as El Niño may change $(21,22)$.

\section{Impacts of Climate on Disease}

Plant disease. Climate change can influence plant disease by altering biological processes of the pathogen, host, or disease-spreading organisms. Direct effects on pathogens are likely to be strongest, although different pathogen life stages may vary in their climatic susceptibilities. Winter is a major period of pathogen mortality, potentially killing more than $99 \%$ of the pathogen population annually (26). Greater overwintering success of pathogens will likely increase disease severity. Because temperatures are expected to increase more in winter than in other seasons, this population bottleneck may be removed for many pathogens.

Several plant diseases are more severe after mild winters or during warmer temperatures (27), which suggests that directional climate warming will alter plant disease severity (23). For example, laboratory and Australian field studies indicate that the fungus causing Mediterranean oak decline, Phytophthora cinnamomi, causes more severe root rot at higher temperatures than the current Mediterranean average (28). In a 14-year field study in England, the Dutch elm disease fungus (Ophiostoma novoulmi) caused greater defoliation in warmer years (29). In a 39-year dendrochronological study in Maine, beech bark cankering by Nectria spp. was worse after mild winters or dry autumns-conditions favoring survival and spread of the beech scale insect, which predisposes beech to fungal infection (30). Wheat stripe rust (Puccinia striiformis) in the Pacific Northwest was less severe during years of low temperature and rainfall from 1969 to 1986 (18).

The number of generations for polycyclic pathogens and seasonal growth of other pathogens may increase under climate change through two mechanisms - longer growing seasons and accelerated pathogen development. Temperature optima for within-host growth of fungal pathogens are generally $20^{\circ}$ to $25^{\circ} \mathrm{C}$, with maxima of $30^{\circ} \mathrm{C}$ or higher $(31,32)$, so this time a critical variable. Because night temperatures are projected to increase more than day temperatures, climate warming may increase or decrease fungal infection and sporulation, depending on whether temperatures move closer to or farther from the typical optimum of $24^{\circ} \mathrm{C}(32)$ (Fig. 1).

Climatic variation can also influence host resistance and growth. Warming can decrease plant resistance to both fungi and viruses (27). Plant species that have faster growth rates in warmer climates may also experience increased disease severity, because higher host density increases the
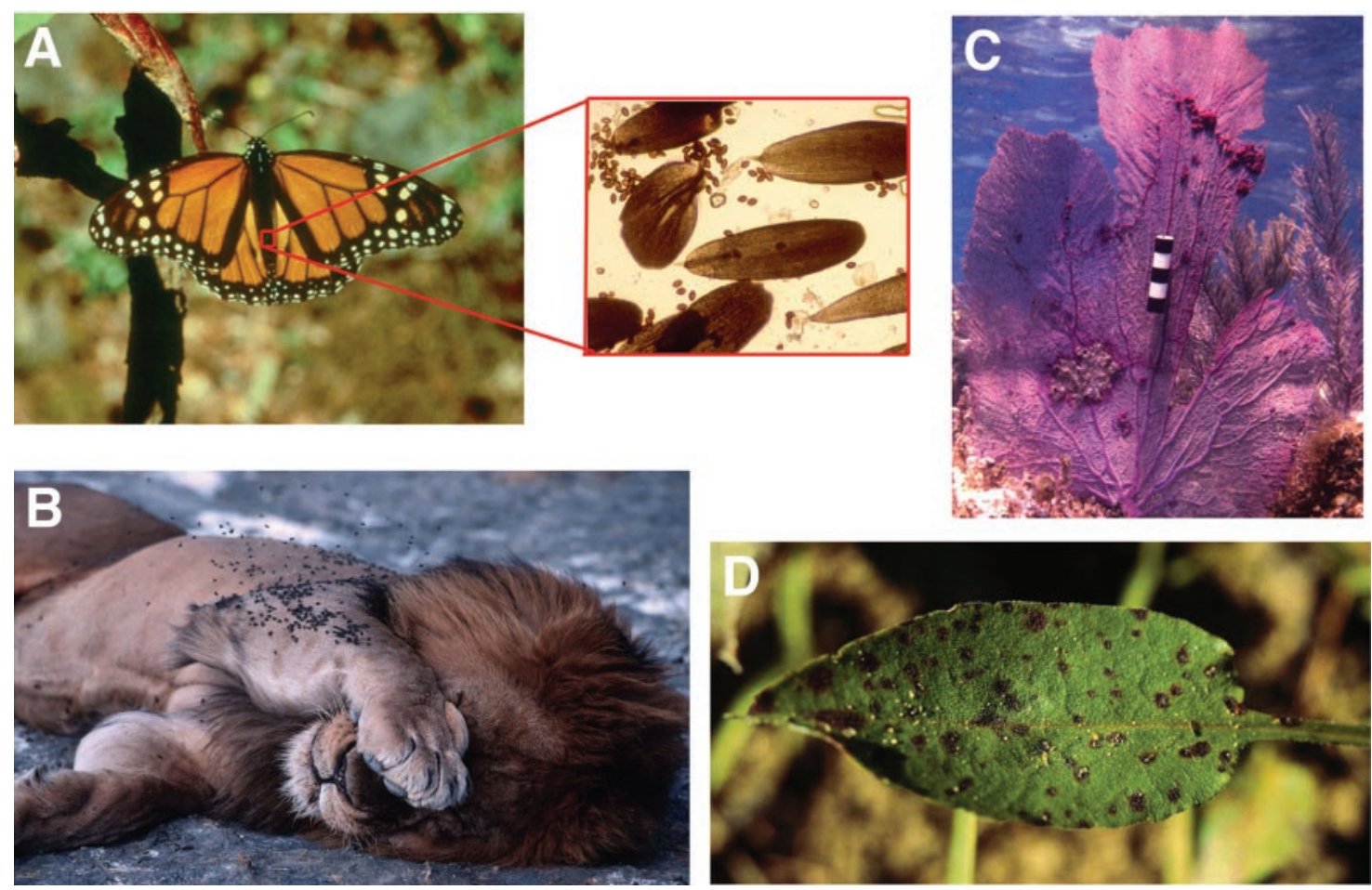

ig. 1. Diseases of potential conservation significance or with climate links. (A) Spores of the protozoan parasite arming that extends the breeding season of their hosts in temperate North America may also increase the prevalence f this disease, and heavily infected populations currently persist in mild climates where hosts breed year-round. [Photos by Karen Oberhauser and De Cansler] (B) Diseased lion infested with Stomoxys flies during a canine distemper outbreak (81) in the Ngorongoro Crater, Africa (February 2001). [Photo by Craig Packer] (C) Lesions and tumors on sea fans Gorgonia ventalina) caused by the temperature-sensitive fungus Aspergillus sydowii. Scale bar, $5 \mathrm{~cm}$. [Photo by Kiho Kim] (D) A leaf spot disease of Aster azureus caused by the fungus Septoria sp. The spread of such foliar fungal pathogens often depends critically on temperature and moisture. [Photo by Charles Mitchell]

effects of climate warming on growth will depend on pathogens and locales. Because of nonlinear effects of temperature on growth, the effect of climate warming on pathogen growth rate will depend not only on changes in mean temperature, but also on temperature variability (31).

For foliar fungi, temperature and water availability interact to determine fungal infection (initial penetration of the plant) and sporulation. Both infection and sporulation often require close to $100 \%$ relative humidity. These moist conditions occur most commonly during overnight dewfall, making temperature at transmission of many pathogens (33).

Also, increased above ground plant biomass influences canopy humidity, which often affects foliar fungal disease spread (32).

The most severe and least predictable disease outbreaks might occur if climate change alters host or pathogen geographic ranges, causing formerly disjunct species and populations to converge (34). The potential for such outbreaks is illustrated by the import of Asian chestnut and European elm logs to the United States, thereby introducing chestnut blight and Dutch elm disease, which then spread rapidly through their new hosts $(8$, 


\section{SCIENCE'S COMPASS}

35). Conversely, after the introduction of wheat from the Old World to Brazil and coffee from Africa to Asia, each crop suffered epidemics caused by fungi native to its new habitat $(36,37)$.

Wildlife diseases. Climate change is most likely to affect free-living, intermediate, or vector stages of pathogens infecting terrestrial animals. Of these, vector-borne diseases are the strongest candidates for altered abundance and geographic range shifts because rising temperatures will affect vector distribution, parasite development, and transmission rates (38). Many vector-transmitted diseases are climate limited because parasites cannot complete development before the vectors die. Vector-borne human pathogens such as malaria, African trypanosomiasis, Lyme disease, tick-borne encephalitis, yellow fever, plague, and dengue have increased in incidence or geographic range in recent decades $(39,40)$. Similarly, vector-borne diseases of livestock, particularly African horse sickness and bluetongue viruses, recently expanded their ranges (27). Most of these diseases have expanded into regions of higher latitude, in each case accompanied by apparent expansion in the ranges of mosquito, tick, and midge vectors. Whether these expansions are due primarily to climate change or other anthropogenic influences (e.g., habitat alteration or drug-resistant pathogen strains) is controversial, as is predicting future distributional changes in disease prevalence. For example, location-specific, long-term data show that climate did not change in an African highland area where malaria increased (41). In fact, expansion of antimalarial resistance and failed vector control programs are probably as important as climate factors in driving recent malaria expansions.

The hypothesis that warming in recent decades has caused latitudinal shifts of vectors and diseases is supported by laboratory and field studies showing that (i) arthropod vectors and parasites die or fail to develop below threshold temperatures (42); (ii) rates of vector reproduction, population growth, and biting increase (up to a limit) with increasing temperature; and (iii) parasite development rates and period of infectivity increase with temperature (42). Another line of evidence supporting strong links between climate and vector-borne disease consists of correlations between warmer, wetter conditions associated with El Niño events and outbreaks of malaria, dengue, Rift
Valley fever, African horse sickness, and plague (27). Correlations between El Niño events and disease outbreaks, however, are not perfect, in part because El Niño does not always

parasites is timing of hypobiosis, or arrested development, determined by temperature and moisture (27). For example, in Trichostrongylus tenuis, a nematode parasite of red grouse, larval hypobiosis occurs during winter and is responsible for seasonal disease occurrence and springtime mortality in red grouse (46).

Disease and climate-mediated synergies affect many wild avian populations. Field and laboratory studies demonstrate that avian malaria (Plasmodium relictum) and pox (Poxvirus avium) introduced into Hawaii caused marked declines in endemic forest birds (Fig. 3) (47), and that disease risk follows an elevation gradient. Malaria and pox transmission are more intense in mid-elevation forests where mosquitoes and endemic birds have the greatest overlap, and are lowest at high elevations where mosquitoes are limited by cool temperatures. Transmission of malaria and pox therefore varies from endemic transmission in warm, low-elevation forests to irregular outbreaks at mid-elevation forests. Temperature differ-

produce heavy rains, and in part because other biophysical and epidemiological factors are involved (43).

Helminth parasites of terrestrial wildlife that release eggs or free-living stages into the environment or use invertebrate intermediate hosts are susceptible to changes in temperature and humidity at several stages of their life cycles. Bioclimatographs that combine local data on moisture and temperature have traditionally been used to monitor and predict outbreaks of gastrointestinal nematodes of livestock. Several processes control associations between climate and the abundance and geographic range of nematodes and other macroparasites. First, development and embryonation success are temperature dependent in larval parasites, and a degree-days concept is widely used to establish conditions that optimize parasite growth (44). For example, in Schistosoma mansoni, a human pathogen in an intermediate host, a $10^{\circ} \mathrm{C}$ increase in temperature can cut development time in half [from 35 to 12 days (45)]. However, predicting the net impact of climate warming on these parasites is difficult because warming increases both development rates and larval mortality rates. Resolving the impact of climate warming in such systems remains a research priority. Another climate-sensitive process in terrestrial nematodes and other ences along this gradient affect factors that contribute to vector capacity and determine the basic reproductive ratio of this disease (48), including the abundance of mosquito vectors, vector oviposition rate, larval development, adult survival, biting rate, and incubation time (27). These factors contribute to vector capacity and determine the basic reproductive ratio of this disease (48) in birds.

The spread of certain viral, protozoan, and nematode parasites in temperate insects may be favored by warmer climates that increase the host's breeding season. Prevalence of the protozoan parasite Ophryocystis elektroscirrha (Fig. 1) is higher in monarch butterfly populations that breed year-round in warm regions than in more seasonal climates where monarchs migrate long distances between breeding intervals (49). Substantial decay of gypsy moth nuclear polyhedrosis virus on host egg cases during winter results in small epidemics early in the summer, followed by a larger wave of infection later in the season (50). Thus, conditions that enhance pathogen winter survival or extend host breeding periods should increase the abundance of many viral and protozoan insect parasites.

Warming might limit certain emerging wildlife diseases. Amphibian population declines in Central America and Australia are linked to emerging chytrid and iridoviral dis- 


\section{SCIENCE'S COMPASS}

eases (1). The geographic ranges of the chytrid epizootic are currently limited by a requirement for cool, moist, high-altitude conditions; hence, this pathogen may be one of a few for which climate warming could disrupt disease spread (27). Entomopathogenic fungi of insects are also projected to decrease with climate warming. Fungal entomopathogens typically have higher prevalence and cause greater mortality under cool, humid conditions. The gypsy moth fungus (Entomophaga maimaiga) released to North America in the early 1900s did not affect host populations until the cool, wet spring of 1989 (51). Outbreaks of another insect pathogen (Entomophthora muscae) in muscoid flies usually coincide with periods of high rainfall and cool temperatures (52). Hot, dry conditions are thought to limit fungal growth and sporulation and may also enhance insect immunity and behavioral fevers (52). Thus, climate warming may limit some fungal entomopathogens and release insects from pathogen pressure (27).

Significant climate change will restructure communities as the current geographic ranges of species shift poleward. If vector-transmitted pathogens expand their ranges out from the tropics, they will experience a decreased diversity of hosts in temperate environments. This will focus the biting activities of their vectors on a less diverse host community, increasing the impact of pathogens on potentially novel hosts and reducing the dilution effect proposed by Schmidt and Ostfeld (53). Ecological restructuring and impacts on parasite-host relationships have at least three important implications for terrestrial conservation biology: (i) increasing the spread of pathogens into the temperate zone, where lower net biodiversity should reduce buffering effects that occur in more diverse tropical communities (53); (ii) triggering elevational changes of pathogen distribution in mountainous regions; and (iii) modifying seasonal patterns of pathogen outbreaks in temperate regions (Fig. 2).

Marine diseases. Recent papers have shown links between pathogens and changing ocean temperatures, including human diseases such as cholera $(19,54)$ and emerging coral pathogens

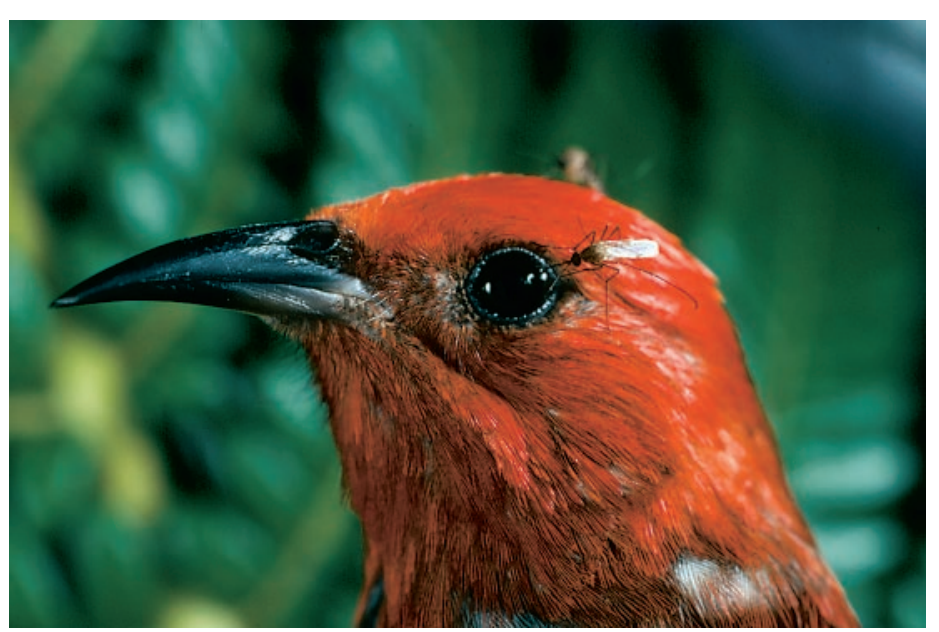

Fig. 3. Culex mosquitoes are the vectors responsible for transmitting avian malaria (Plasmodium relictum) and avian pox (Poxvirus avium) to endemic Hawaiian forest birds such as the apapne (Himatione sanguinea). [Photo by Jack Jeffrey]
(58). Three coral pathogens grow well at temperatures close to or exceeding probable host optima, which suggests that they would increase in warmer seas (27) (Fig. 1). The bacterium Vibrio shiloi is temperature sensitive and causes bleaching in the coral Oculina patagonica (59). Heat-induced viruses could also be involved in temperature-induced coral bleaching (60). Another climatic anomaly hypothesized to initiate coral disease is transport of aeolian dust from Saharan Africa (mediated by a shift in the North Atlantic Oscillation) to the Caribbean (61).

Growth rates of marine bacteria (62) and fungi (63) are positively correlated with temperature. Among marine fungi, optimum temperatures for growth coincide with thermal stress and bleaching for many corals $(63,64)$, leading to likely co-occurrence of bleaching and fungal infection. Among marine invertebrates and eelgrass, many epizootics of unidentified pathogens are linked to temperature increases, but the mechanisms for pathogenesis are unknown (27). In 1999, gorgonian corals, scleractinian corals, zoanthids, and sponges in the Ligurian Sea were affected by a temperature-linked epizootic, where mortality likely resulted from the effects of environmental stress and an unidentified opportunistic pathogen (65). Although many disease-related mass mortalities in the ocean are associated with warming waters, coldwater ease on the U.S. east coast (Perkinsus mari$n u s$ ) extended its range from Long Island to Maine during a winter warming trend in which the winter cold-water barrier to pathogen growth was removed. El Niño events are also implicated in Eastern oyster diseases in the Gulf of Mexico, where Perkinsus is endemic. Gulf-wide $P$. marinus infection intensity and prevalence drop during cold, wet El Niño events and rise during warm, dry La Niña events (69).

Although there is evidence for temperature- and climate-related links in some marine diseases, lack of reliable baselines and incomplete disease time series complicate the partitioning of climate effects and other anthropogenic disturbances. A time series sufficiently long to detect climate effects is only available for oyster disease (70) and cholera $(19,71)$. Hayes et al. (25) posit a detectable increase in biological disturbances related to the North Atlantic Oscillation, but lack of baselines prevents accounting for the contribution of other anthropogenic factors such as eutrophication, overfishing (72), and aquaculture.

\section{Conclusions}

Links between climate change and disease will increase the severity of threats associated with climate warming. Increased disease can contribute to population or species declines, especially for generalist pathogens infecting multiple host species. The greatest impacts of disease may result from a relatively small number of emergent pathogens. Epidemics caused when these infect new hosts with little resistance or tolerance may lead to population declines, such as those that followed tree pathogen invasions in North America during the last century. Although we have emphasized threats of intensified parasitism, the loss of parasites can also affect biodiversity by releasing hosts from a major source of population regulation.

The most detectable effects of directional climate warming on disease relate to geographic range expansion of pathogens such as Rift Valley fever, dengue, and Eastern oyster disease. Factors other than climate change-such as changes in (55). The coral bleaching associated with the 1998 El Niño event was the most geographically extensive and severe in recorded history $(56,57)$, causing pronounced mortality worldwide. Although reported only as bleaching-related mortality, the demise of some corals in the 1998 bleaching was accelerated by opportunistic infections, such as the mass mortality of the gorgonian coral Briareum asbestinum disease of salmonids is favored by low temperatures. Signs of infection appear when water temperatures are $4^{\circ}$ to $10^{\circ} \mathrm{C}$ and disappear in warmer water (66).

Increased ocean temperature also causes pathogen range expansions. A notable example is the mid-1980s northward expansion of oyster diseases $(67,68)$. Eastern oyster dis- land use, vegetation, pollution, or increase in drug-resistant strains - may underlie these range expansions. Nonetheless, the numerous mechanisms linking climate warming and disease spread support the hypothesis that climate warming is contributing to ongoing range expansions.

We found no unequivocal examples of nat- 


\section{SCIENCE'S COMPASS}

ural changes in severity or prevalence resulting from directional climate warming per se. However, current data on temperature-dependent pathogen development and replication rates, and on associations between disease occurrence and climate variation, suggest several ways in which climate warming has altered and will alter disease severity or prevalence. In the temperate zone, shorter, milder winters are expected to increase disease spread. In tropical oceans, warmer summers may increase host susceptibility through thermal stress. Decreased severity or prevalence with increasing temperature is expected for several types of diseases, such as amphibian chytridiomycosis, coldwater disease of fish, and fungal pathogens of insects.

Given the challenge of linking disease impacts and directional climate change for wellstudied agricultural, maricultural, and human diseases, it is not yet possible to predict the consequences for biodiversity. Very few empirical studies directly explore the relationship between climate and transmission of or resistance to disease. Even fewer explore interactions between temperature and components of a pathogen's life cycle $(29,73,74)$. We therefore identify four priorities for research to improve our ability to predict impacts of climate change on disease:

1. Collect baseline data on diseases of wild populations. Baseline disease data are critical to predict changes in a warming climate, but such data are rarely collected for nonhuman, nonagricultural, or noncommercial systems. Monitoring programs for the prevalence and severity of wildlife diseases and their population- and community-level impacts must be implemented for a wider range of natural systems.

2. Separate the effects of multiple climate variables on disease. To accurately predict future responses to climate change, we must quantify the direct and synergistic effects of multiple climate variables, such as temperature and moisture, on disease. Separating the effects of these variables will require experimental manipulation in the lab or field. Pathogens with complex life cycles present a particular challenge because different life stages may be affected by variables with opposite effects on parasite fitness.

3. Forecast epidemics. Forecasting models using climate variables can effectively predict outbreaks for some crop and human diseases. Crop disease programs have long been in effect: Potato late blight (Phytophora infestans) is correctly forecasted $92 \%$ of years on the basis of number of days of rain (75), and rice blast (Pyricularia oryzae) models based on temperature and moisture forecast when an epidemic will start and when to apply fungicide for optimal control (76). Such forecasting programs are also in development for human diseases with climate sensitivity, such as Rift Valley fever, which is associated with warm El Niño events of high rainfall $(43,77)$, and cholera is predictable from sea surface temperature associations with El Niño (19). The National Oceanic and Atmospheric Administration's coral bleaching program uses sea surface temperature increases in a location-specific algorithm to predict when and where coral bleaching will occur (78). Similar disease forecasting models should be developed for other threatened populations and coupled to models predicting epidemic impacts on host abundance. Implementing such forecasting systems for diseases of threatened populations would allow intervention before climate-induced epidemics endanger host populations.

4. Evaluate the role of evolution. The rate of adaptation and evolution is an important unknown in any prediction of climate impacts (79). Overlooking the role of evolution can be particularly dangerous with infectious diseases (80). If shifts in host or parasite ranges lead to disease emergence, the rate of pathogen evolution and host evolutionary response could be critical to predicting disease spread and subsequent effects on biological diversity.

\section{References and Notes}

1. P. Daszak et al., Emerg. Infect. Dis. 5, 735 (1999).

2. P. Daszak et al., Science 287, 443 (2000).

3. , Trends Ecol. Evol. 14, 279 (1999).

4. A. A. Cunningham et al., Conserv. Biol. 12, 1139 (1998).

5. E. Rasmussen, in Seagrass Ecosystems, P. McRoy and C. Helfferich, Eds. (Dekker, New York, 1977), Pp. 1-51.

6. R. Woodroffe, Anim. Conserv. 2, 185 (1999).

7. M. Friend et al., Acta XX Congressus Internationalis Ornithologici IV, B. D. Bell et al., Eds. (New Zealand Ornithological Congress Trust Board, 1991), pp. 2331-2337.

8. S. L. Anagnostakis, Mycologia 79, 23 (1987).

9. P. A. Opler, in The American Chestnut Symposium, W. McDonald, Ed. (Univ. of West Virginia Press, Morgantown, WV, 1979), pp. 83-85.

10. G. Weste et al., Annu. Rev. Phytopathol. 25, 207 (1987).

11. D. J. Mattson et al., in Whitebark Pine Communities: Ecology and Restoration, D. F. Tomback, S. F. Arno, R. E. Keane, Eds. (Island Press, Washington, DC, 2001), pp. 121-136.

12. G. C. Daily et al., Proc. Natl. Acad. Sci. U.S.A. 90, 592 (1993).

13. G.-R. Walther et al., Nature 416, 389 (2002).

14. D. J. Marcogliese, Can. J. Zool. 79, 1331 (2001).

15. E. Green, A. Bruckner, Biol. Conserv. 96, 347 (2000).

16. D. Rind, in Global Changes in the Perspective of the Past, J. A. Eddy and H. Oeschger, Eds. (Wiley, Chichester, UK, 1993), pp. 36-49.

17. J. M. Kiesecker et al., Nature 410, 681 (2001).

18. H. Scherm et al., Phytopathology 85, 970 (1995).

19. M. Pascual et al., Science 289, 1766 (2000).

20. M. P. Hoerling et al., Science 292, 90 (2001).

21. D. B. Enfield, Oceanography 1, 23 (1988).

22. D. T. Rodbell et al., Science 283, 516 (1999).

23. S. M. Coakley et al., Annu. Rev. Phytopathol. 37, 399 (1999).

24. J. T. Houghton et al., Eds., Climate Change 2001: The Scientific Basis (Cambridge Univ. Press, Cambridge, 2001).

25. M. L. Hayes et al., Hydrobiologia 460, 213 (2001).

26. J. J. Burdon, T. Elmquist, Plant Pathol. 45, 933 (1996).

27. A supplementary table is available on Science Online.

28. C. M. Brasier, Ann. Sci. For. 53, 347 (1996).

29. M. L. Sutherland, S. Pearson, C. M. Brasier, Phytopathology 87, 576 (1997)

30. D. R. Houston, H. T. Valentine, Can. J. For. Res. 18, 38 (1987).

31. H. Scherm et al., Phytopathology 84, 1380 (1994).
32. H. A. McCartney, in Environmentally Safe Approaches to Crop Disease Control, N. A. Rechcigl and J. E. Rechcigl, Eds. (CRC Press, Boca Raton, FL, 1997), pp. 3-31.

33. J. J. Burdon et al., Annu. Rev. Phytopathol. 20, 143 (1982).

34. M. B. Davis, R. G. Shaw, Science 292, 673 (2001).

35. F. W. Holmes, in Vectors of Plant Pathogens, K. Harris, K. Maramorosch, Eds. (Academic Press, New York, 1980), pp. $133-148$

36. G. L. Carefoot et al., Famine on the Wind, Man's Battle Against Plant Disease (Rand McNally, Chicago, 1967).

37. B. Valent, Phytopathology 80, 33 (1990).

38. R. S. Kovats et al., Philos. Trans. R. Soc. London Ser. B 356, 1057 (2001).

39. N. G. Gratz, Annu. Rev. Entomol. 44, 51 (1999).

40. E. Lindgren, L. Talleklint, T. Polfeldt, Environ. Health Perspect. 108, 119 (2000)

41. S. I. Hay et al., Nature 415, 905 (2002).

42. J. A. Patz et al., Trop. Med. Int. Health 3, 818 (1998).

43. K. J. Linthicum et al., Science 285, 397 (1999).

44. G. Smith, Parasitology 101, 309 (1990).

45. R. M. Gordon et al., Ann. Trop. Med. Parasitol. 28, 323 (1934).

46. P. J. Hudson, D. N. Newborn, P. J. Robertson, Wildlife Biol. 2, 79 (1997).

47. C. T. Atkinson, R. J. Dusek, K. L. Woods, W. M. Iko, J. Wildlife Dis. 36, 197 (2000)

48. E. Massad, O. P. Forattini, Ecosyst. Health 4, 119 (1998).

49. S. M. Altizer, K. S. Oberhauser, L. P. Brower, Ecol. Entomol. 25, 125 (2000).

50. G. Dwyer, J. S. Elkinton, J. Anim. Ecol. 62, 1 (1993).

51. A. E. Hajek, R. A. Humber, J. S. Elkinton, Am. Entomol. 41, 31 (1995)

52. D. W. Watson et al., J. Invertebr. Pathol. 61, 10 (1993)

53. K. A. Schmidt, R. S. Ostfeld, Ecology 82, 609 (2001).

54. R. R. Colwell, Science 274, 2025 (1996).

55. J. W. Porter et al., Hydrobiologia 460, 1 (2001).

56. C. Wilkinson et al., Ambio 28, 188 (1999).

57. O. Hoegh-Guldberg, Mar. Freshw. Res. 50, 839 (1999).

58. D. Harvell et al., Hydrobiologia 460, 97 (2001).

59. A. Kushmaro, E. Rosenberg, M. Fine, Y. Ben Haim, Y. Loya, Mar. Ecol. Prog. Ser. 171, 131 (1998).

60. W. H. Wilson et al., Aquat. Microb. Ecol. 25, 99 (2001).

61. E. A. Shinn et al., Geophys. Res. Lett. 27, 3029 (2001).

62. F.-K. Shiah et al., Mar. Ecol. Prog. Ser. 103, 297 (1994).

63. G. U. Holmquist et al., J. Food Sci. 48, 778 (1983).

64. S. L. Coles, P. L. Jokiel, C. R. Lewis, Pac. Sci. 30, 159 (1976).

65. C. Cerrano et al., Ecol. Lett. 3, 284 (2000).

66. R. A. Holt et al., J. Aquat. Anim. Health 1, 94 (1989).

67. S. E. Ford, J. Shellfish Res. 15, 45 (1996).

68. T. Cook et al., Estuar. Coast. Shelf Sci. 46, 587 (1998).

69. E. N. Powell et al., J. Shellfish Res. 15, 141 (1996).

70. E. Hofmann et al., Hydrobiologia 460, 195 (2001).

71. B. Lobitz et al., Proc. Natl. Acad. Sci. U.S.A. 97, 1438 (2000).

72. J. B. C. Jackson et al., Science 293, 629 (2001).

73. A. P. Dobson et al., in Global Warming and Biological Diversity, R. L. Peters and T. E. Lovejoy, Eds. (Yale Univ. Press, New Haven, CT, 1992), pp. 201-217.

74. A. P. Dobson et al., Lancet 342, 1096 (1993).

75. D. A. Johnson et al., Phytopathology 86, 480 (1996).

76. K. Ishigura, A. Hashimoto, in Rice Blast Modelling and Forecasting, P. S. Teng, L. R. Pollard, G. Argosino, Eds. (International Rice Research Institute, Seoul, South Korea, 1991), pp. 39-53.

77. A. Anyamba et al., Cad. Saude Publica 17 (suppl.), 133 (2001).

78. A. E. Strong et al., Reef Encounters 24, 20 (1998).

79. J. R. Etterson et al., Science 294, 151 (2001).

80. S. R. Palumbi, Science 293, 1786 (2001).

81. C. Packer et al., J. Anim. Ecol. 68, 1161 (1999).

82. We thank J. Reichmann and the National Center for Ecological Analysis and Synthesis for supporting the working group on Diseases and Conservation run by A.P.D. and a sabbatical for C.D.H., C. Greene for oceanographic and climate advice, and L. Gerber and K. Kim for comments on the manuscript. Also supported by NSF grant OCE 9818830 (C.D.H.).

\section{Supplementary Online Material}

www.sciencemag.org/cgi/content/full/296/5576/2158/

DC1

Table S1 